Marquette University

e-Publications@Marquette

College of Nursing Faculty Research and

Publications

Nursing, College of

$11-2012$

\title{
A Retrospective Study of the Relationship Between Back Pain and Unilateral Knee Osteoarthritis in Candidates for Total Knee Arthroplasty
}

\author{
David R. Burnett \\ University of Louisville \\ Naira H. Campbell-Kyureghyan \\ University of Wisconsin - Milwaukee \\ Robert V. Topp \\ Marquette University, robert.topp@marquette.edu \\ Peter M. Quesada \\ University of Louisville \\ Patricia B. Cerrito \\ University of Louisville
}

Follow this and additional works at: https://epublications.marquette.edu/nursing_fac

Part of the Nursing Commons

\section{Recommended Citation}

Burnett, David R.; Campbell-Kyureghyan, Naira H.; Topp, Robert V.; Quesada, Peter M.; and Cerrito, Patricia B., "A Retrospective Study of the Relationship Between Back Pain and Unilateral Knee Osteoarthritis in Candidates for Total Knee Arthroplasty" (2012). College of Nursing Faculty Research and Publications. 348.

https://epublications.marquette.edu/nursing_fac/348 
Marquette University

e-Publications@Marquette

\section{Nursing Faculty Research and Publications/College of Nursing}

This paper is NOT THE PUBLISHED VERSION; but the author's final, peer-reviewed manuscript. The published version may be accessed by following the link in the citation below.

Orthopaedic Nursing, Vol. 31, No. 6 (November/December 2012): 336-343. DOI. This article is (C) National Association of Orthopaedic Nurses and permission has been granted for this version to appear in e-Publications@Marquette. National Association of Orthopaedic Nurses does not grant permission for this article to be further copied/distributed or hosted elsewhere without the express permission from National Association of Orthopaedic Nurses.

\section{A Retrospective Study of the Relationship Between Back Pain and Unilateral Knee Osteoarthritis in Candidates for Total Knee Arthroplasty}

David R. Burnett

Department of Industrial Engineering, University of Louisville, Louisville, KY.

Naira H. Campbell-Kyureghyan

Department of Industrial and Manufacturing Engineering, University of Wisconsin-Milwaukee.

Robert V. Topp

College of Nursing, Marquette University, Milwaukee, WI.

Peter M. Quesada

Department of Mechanical Engineering, University of Louisville, Louisville, KY.

Patricia B. Cerrito

Department of Mathematics, University of Louisville, Louisville, KY. 


\section{Abstract}

The purpose of this study was to determine the presence and temporal relationship between back pain and knee osteoarthritis (OA). All subjects were candidates for unilateral total knee arthroplasty (TKA) to relieve knee pain related to $O A$, and information regarding the prevalence of back pain was collected via questionnaires. $A$ total of 42 subjects with unilateral knee OA responded to the questionnaires, and $74 \%$ of subjects reported chronic back pain, which first occurred approximately 10 years before their becoming candidates for TKA. All but 1 subject reported the onset of back pain prior to TKA candidacy, and less than $15 \%$ of subjects felt that their worst back pain occurred after the onset of knee OA. The results of this study are a first step toward quantifying the temporal relationship between back pain and unilateral knee $O A$, and future studies will look to assess potential risk factors for knee OA such as strength, biomechanical, and anatomical asymmetry.

It has been estimated that $15 \%$ of the adult population, and two of three persons older than 45 years, suffer from musculoskeletal problems (Lawrence et al., 1998; Wegener, Belza, \& Gall, 1996). Joint pain is experienced by most people at some point in their lifetime and seven of eight sufferers report pain in multiple joints (Keenan, Tennant, Fear, Emery, \& Conaghan, 2006). However, the focus of current research and clinical practice is directed at individual joints and does not consider the temporal or causal relationships between multiple joint pain within individuals (Keenan et al., 2006). Two areas that are commonly characterized by pain are the knee(s) and the spine.

Osteoarthritis (OA), which typically affects weight-bearing joints, is the most common source of joint pain, impacting approximately 21 million Americans (Felson \& Zhang, 1998), the majority of whom are older than 45 years (Wegener et al., 1996). Characteristics of knee OA include progressive declines in strength, flexibility, and function, accompanied by increases in joint pain (Creamer, 2004). It has been observed that knee OA is accompanied by pain in other joints, including the hip and spine, and has been linked with bone demineralization, muscle atrophy, inflexibility, and loss of functional ability (Goerres, Häuselmann, Seifert, Michel, \& Uebelhart, 2005).

A total of 26-31 million Americans have back pain (R. Deyo, Mirza, \& Martin, 2006; Lawrence et al., 1998; Snook \& Webster, 1987), and the lifetime prevalence is estimated at $70 \%-80 \%$ (Centers for Disease Control and Prevention, 2001; R. A. Deyo, 1998). Back pain is one of the leading causes for visits to a physician, hospitalization, and surgery (R. A. Deyo, 1998; Snook \& Webster, 1987) and the costliest healthcare problem for people aged 30-50 years (Bigos et al., 1994). Experts estimated that the annual combined costs of medical care and disability compensations for back pain in the United States could exceed \$50 billion (R. A. Deyo, 1998), with almost 220,000 back injuries in 2008 (BLS, 2008).

Limited research exists on the relationship between knee pain and back pain. Keenan et al. (2006) reported that people were 12 times as likely to have multiple joint problems involving either the knee or the back than to have pain in only one of those joints. Muscle strength of the trunk and lower extremities is generally much weaker in subjects with chronic low back pain (Lee, Ooi, \& Nakamura, 1995) or lumbar disc herniation (Ho et al., 2005). Suter and Lindsay (2001) concluded that chronic low back pain or reduced endurance of the back musculature is associated with significant inhibition of the knee extensors, particularly inhibiting the knee joint to fully extend. This association was not found in healthy subjects (Liikavainio et al., 2007).

Only one study has examined the presence of back pain in patients with knee OA. Wolfe, Hawley, Peloso, Wilson, and Anderson (1996) found that $54.6 \%$ of patients with knee OA experienced back pain, and $31 \%$ were experiencing back pain on the day of their examination. In addition, while epidemiologic studies have indicated the onset of back pain and knee pain in the fifth and sixth decades, respectively (Felson et al., 2000), no research has attempted to specifically examine the temporal relationship between chronic low back pain and knee OA, which is a necessary first step to determining any potential causal relationship between low back pain and knee 
OA. The purpose of this study was to determine the presence and temporal relationship between low back pain and knee OA. It is hypothesized that (1) a majority of individuals with unilateral knee OA will also have low back pain and (2) individuals with unilateral knee OA will report chronic low back pain prior to the onset of knee OA.

\section{Materials and Methods}

\section{Subjects}

Community-residing subjects who were involved in an ongoing randomized controlled trial (Topp, Swank, Quesada, Nyland, \& Malkani, 2009) at the University of Louisville were recruited to participate in this retrospective descriptive study. As participants of the ongoing randomized controlled trial, all subjects were clinically evaluated by their personal surgeon and determined to be candidates for unilateral total knee arthroplasty (TKA) to relieve joint pain related to OA. Because moderate-intensity exercise was required for the original randomized controlled trial (Topp et al., 2009), potential subjects were excluded if they reported a history of uncontrolled angina, cardiomyopathy severe enough to compromise cardiac functioning, any other health problem that inhibits moderate exercise, or if they were currently taking nitrates, digitalis, or phenothiazines. A total of 61 subjects met the inclusion criteria and were invited to participate in the study by completing a single questionnaire. A summary of subject demographics is given in Table 1.

Table 1: Summary of Subject Demographics

\begin{tabular}{|l|l|l|l|}
\hline UKOA Respondent & Age Average & Height Average & Weight Average \\
\hline Group & (6SD) & (6SD) (cm) & (6SD) (kg) \\
\hline With low back pain & $63.1(7.26)$ & $167.1(10.7)$ & $97.9(29.2)$ \\
\hline Without low back pain & $63.0(10.0)$ & $170.8(11.3)$ & $99.9(16.4)$ \\
\hline
\end{tabular}

Note. UKOA = unilateral knee osteoarthritis.

\section{Questionnaire}

The customized questionnaire used in this study was divided into four sections: (1) personal details; (2) musculoskeletal pain; (3) upper back pain; and (4) low back pain. The first section requested information concerning the subjects' current or former occupation, as well as their perceptions regarding the cause(s) of their unilateral knee pain. The subjects were also asked whether or not they currently had back pain (upper or lower) or had ever undergone back surgery. Subjects were asked whether or not they had ever injured their back in an accident or work setting, and additional information regarding the severity of the back pain was also requested (i.e., lost workdays, change of work duties, physician/chiropractor visits). The subjects reported the year when their back pain first occurred as well as the year of their worst back pain. All information regarding musculoskeletal pain in the neck, shoulders, elbows, hands/wrists, upper back, lower back, hips/thighs/buttocks, and ankles/feet both before and after the onset of knee problems was collected via a customized Standardized Nordic Questionnaire (SNQ) (Kuorinka et al., 1987). Section 2 (Musculoskeletal Pain) was customized to ascertain information concerning the presence of joint pain "prior to knee problems," "after knee problems," and "in the last 14 days." The original SNQ used the terms "last 12 months" and "last 7 days." The names of the most joints (neck, shoulder, elbow, wrist/hands, upper back, and lower back) were identical to the original SNQ; however, "hips/thighs" from the original SNQ was changed to "hips/thighs/buttocks." Also, specific information (cause of pain, change of duties, etc.) was collected only with respect to upper back pain and lower back pain and not every joint as is done in the original SNQ.

The SNQ was developed by a team of Nordic researchers to create a simple standardized questionnaire that could be used for epidemiologic studies of musculoskeletal disorders (Baron, Hales, \& Hurrell, 1996; Kuorinka et 
al., 1987). The original developers of the SNQ found that the reliability based on a test-retest methodology ranged from $0 \%$ to $23 \%$ disagreement and the validity, when compared to clinical history in two cohorts, ranged from $0 \%$ to $20 \%$ disagreement (Kuorinka et al., 1987). Thus, they concluded that the SNQ was acceptable as a reliable and valid assessment tool. The SNQ is widely used in Europe and has been adapted in the United States by the National Institute for Occupational Safety and Health (Salerno, Copley-Merriman, Taylor, Shinogle, \& Schulz, 2002).

A letter briefly describing the project, the customized SNQ, a self-addressed and stamped envelope for returned responses, and a consent form were all distributed via U.S. Post Office mail. This study protocol was approved by the University of Louisville's institutional review board (\#215.03_05-2-07_AMD).

\section{Data Analysis}

Correlation analysis was completed to assess relationships between survey questions, and Cronbach's alpha was computed to further evaluate internal reliability. Chi-square analysis was used to determine whether or not back pain was associated with pain in other joints. Whereas $p$ values $<.05$ represent statistically significant associations, $p$ values ranging from 0.05 to 0.10 signify marginal associations. All analyses were completed with SAS 9.1 (SAS Institute Inc., Cary, NC).

\section{Results}

\section{Subject Data}

A total of 38 subjects returned the completed questionnaire and signed consent forms via US Postal Service mail. Responses and consent were obtained from an additional seven subjects during telephone or on-site interviews, thus totaling 45 responses (73.8\%). However, three of the respondents replied that they did not wish to take part in the study, which decreased the total number of participants to 42 (72.4\%). The average age of subjects was 63.1 years and ranged from 49 to 85 years. Twenty-nine participants (69\%) were female and 13 were male. The average ( \pm SD) height and weight of male subjects were $180.7( \pm 5.4) \mathrm{cm}$ and $108.2( \pm 18.5) \mathrm{kg}$, respectively. Female height and weight were $162.3( \pm 7.1) \mathrm{cm}$ and $91.5( \pm 22.1) \mathrm{kg}$, respectively. All subjects were right handed, and $64 \%$ of subjects had underwent surgical procedures on their right knees. Thirty percent of subjects were still currently employed. Of the employed persons, $72 \%$ worked more than 30 hours/week and $44 \%$ worked more than 40 hours/week.

\section{Correlation Analysis}

With respect to the correlation analysis (see Table 2), lifetime prevalence of low back pain was positively correlated with all other survey questions and highly correlated with currently having low back pain, severity, frequency, and duration of low back pain. Severity of low back pain was highly correlated with frequency and duration of low back pain and being sent home from work. Having undergone surgery on the spine was highly correlated with a change or reduction in work duties, severity and duration of low back pain, and reduction in leisure activities. Frequency and duration of low back pain showed a negative correlation. Overall, Cronbach's alpha was computed to be .836 and indicates sufficient internal reliability of the questionnaire. 
Table 2: Results of Correlation Analysis-Correlation Coefficients

\begin{tabular}{|c|c|c|c|c|c|c|c|c|c|c|c|c|c|c|c|c|}
\hline LBP Lifetime & LBP Current & Spine Surgery & Accident & Change Duties & Severity & Sent Home & Freq & Duration & Reduce Work & Reduce Leisure & $\mathrm{N}$ & $\mathrm{s}$ & $E$ & W & $\mathrm{H}$ & $A$ \\
\hline LBP 1.0 lifetime & .48 & .27 & .27 & .28 & .82 & .25 & .54 & .66 & .33 & .32 & .30 & .33 & .21 & .13 & .11 & .13 \\
\hline LBP current & 1.0 & .19 & .19 & .25 & .32 & .11 & -.23 & .69 & .36 & .31 & .17 & .35 & .31 & .35 & .31 & .25 \\
\hline Spine surgery & & 1.0 & .04 & .47 & .50 & .24 & -.15 & .43 & .50 & .41 & -.16 & .07 & .02 & .02 & .05 & -.22 \\
\hline Accident & & & 1.0 & .19 & .38 & .36 & .08 & .32 & .44 & .35 & .36 & .07 & .17 & .14 & .42 & .14 \\
\hline Change duties & & & & 1.0 & .44 & .46 & .06 & .40 & .52 & .27 & .19 & .16 & .13 & .15 & .18 & .06 \\
\hline Severity & & & & & 1.0 & .33 & .46 & .59 & .45 & .34 & .20 & .27 & -.04 & .05 & .20 & .10 \\
\hline Sent home & & & & & & 1.0 & .28 & .18 & .34 & .27 & .27 & .01 & .26 & -.25 & .10 & .07 \\
\hline Frequency & & & & & & & 1.0 & -.04 & -.05 & .03 & .23 & -.12 & .07 & -.13 & -.09 & .12 \\
\hline Duration & & & & & & & & 1.0 & .60 & .63 & .19 & .39 & .32 & .43 & .24 & .00 \\
\hline Reduce work & & & & & & & & & 1.0 & .70 & .08 & .13 & .22 & .33 & .33 & .06 \\
\hline Reduce leisure & & & & & & & & & & 1.0 & -.25 & -.04 & .25 & .28 & .04 & -.12 \\
\hline$N$ & & & & & & & & & & & 1.0 & .29 & .40 & .25 & .29 & .37 \\
\hline$S$ & & & & & & & & & & & & 1.0 & .17 & .13 & .08 & .25 \\
\hline$E$ & & & & & & & & & & & & & 1.0 & .36 & .11 & .22 \\
\hline 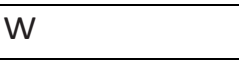 & & & & & & & & & & & & & & 1.0 & .30 & .35 \\
\hline $\mathrm{H}$ & & & & & & & & & & & & & & & 1.0 & .51 \\
\hline A & & & & & & & & & & & & & & & & 1.0 \\
\hline
\end{tabular}

Note. $\mathrm{LBP}=$ low back pain; $\mathrm{N}=$ neck pain; $\mathrm{S}=$ shoulder pain; $\mathrm{E}=$ elbow pain; $\mathrm{W}=$ wrist/hand pain; $\mathrm{H}$ = hips/thighs/buttocks pain; $\mathrm{A}=$ ankle/foot pain. 


\section{Back Pain}

One main focus of this study was to determine the existence of back pain among individuals with unilateral knee $\mathrm{OA}$ and gain a greater understanding of the region (upper back, lower back, or both) and severity of back pain. We hypothesized that the majority of individuals with unilateral knee OA will also have back pain. Figure 1 presents a summary of the information collected from the questionnaires regarding the presence of back pain.

Figure 1: Prevalence of back pain and back surgery among subjects. A negative value is indicative of a subject reporting their first or worst back pain after the onset of knee problems/TKA.

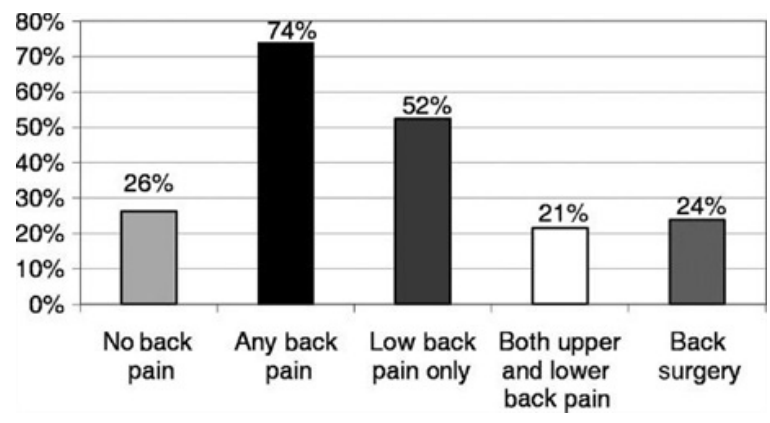

Seventy-four percent of subjects reported having either upper back pain or low back pain at some point during their life. Fifty-two percent of subjects had only low back pain, whereas no subjects reported only upper back pain. The prevalence of both upper back pain and low back pain was reported by $21 \%$ of respondents. In addition, 10 subjects (24\%) reported having undergone spinal surgery. Seventy-seven percent of subjects who reported a lifetime prevalence of back pain also reported that they currently had back pain.

The severity of pain and temporal relationship between upper back pain and low back pain and knee problems was further investigated (see Table 3). Upper back pain and low back pain resulting from an accident were reported by $22 \%$ and $32 \%$ of subjects, respectively. Eleven percent of subjects were forced to change work duties, and $22 \%$ were sent home from work because of upper back pain. Twenty-nine percent were sent home or changed duties because of low back pain. In addition, 22\% (upper back pain) and 42\% (low back pain) of subjects reported a reduction in work activities during the last 12 months. More than half of the respondents had visited a physician or back pain specialists (chiropractor, massage therapists) during the previous 12 months because of upper back pain or low back pain. More than $75 \%$ rated their upper back pain as severe or very severe, whereas $90 \%$ identified their low back pain as severe or very severe.

The temporal relationship between back pain and knee problems was also of major interest. It was found that the onset of back pain preceded knee problems by approximately 16.6 years (see Table 3 ). Also, respondents reported that their worst episode of back pain was present approximately 8.3 years prior to their becoming eligible for TKA. All but one subject reported the onset of back pain prior to TKA candidacy, and only six subjects felt that their worst back pain occurred after the onset of knee problems (see Figure 2). 
Table 3: Summary of Information Regarding Back Pain Reported in the Questionnaires

\begin{tabular}{|l|l|l|l|l|l|l|l|l|}
\hline & & $\begin{array}{l}\text { Change } \\
\text { Duties }\end{array}$ & Sent & $\begin{array}{l}\text { Reduced Work } \\
\text { Activities During the } \\
\text { Last 12 }\end{array}$ & $\begin{array}{l}\text { Reduced Leisure } \\
\text { Activities During } \\
\text { the Last 12 }\end{array}$ & $\begin{array}{l}\text { Seen Doctor } \\
\text { During Last }\end{array}$ & $\begin{array}{l}\text { TKAa - } \\
\text { First Back }\end{array}$ & $\begin{array}{l}\text { TKAa - Worst } \\
\text { Back Pain (Avg. }\end{array}$ \\
\hline & $\begin{array}{l}\text { Accident } \\
(\%)\end{array}$ & $(\%)$ & Home (\%) & Months (\%) & Months (\%) & $\begin{array}{l}12 \text { Months } \\
(\%)\end{array}$ & $\begin{array}{l}\text { Pain (Avg. } \\
\text { Years) }\end{array}$ & $\begin{array}{l}\text { Years) } \\
\text { Upper back painb }\end{array}$ \\
\hline 22 & 11 & 22 & 22 & 33 & 56 & 10.77 & 4.55 \\
\hline Low back painc & 32 & 29 & 29 & 42 & 39 & 55 & 15.97 & 11.30 \\
\hline All back pain & & & & & & & 16.57 & 8.33 \\
\hline
\end{tabular}

${ }^{a}$ Determined by year when the subject became a candidate for TKA.

${ }^{b}$ Among subjects reporting upper back pain $(n=9)$.

${ }^{\mathrm{c}}$ Among subjects reporting low back pain $(n=31)$. 
Figure 2: Temporal relationship between first and worst back pain and total knee arthroplasty (TKA) candidacy.

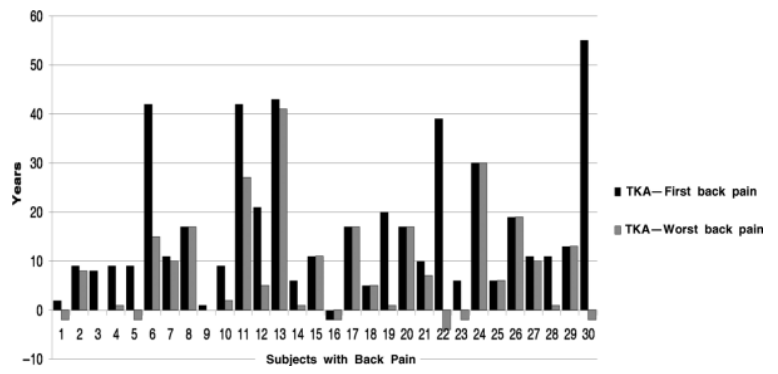

As shown in Figure 2, several subjects reported that the onset of back pain occurred between 20 and 55 years before becoming candidates for TKA. In most of these cases, back pain was a result of a traumatic incident such as a car accident or fall. However, because we were trying to be conservative and not overestimate the temporal relationship, these outliers (defined as being greater than 2 standard deviations away from the mean) were removed for the secondary analysis and it was these findings that are primarily discussed in this study. Even after the removal of outliers, subjects reported that back pain occurred, on average, over 10 years before becoming candidates for TKA.

\section{Additional Musculoskeletal Joint Pain}

Low back (74\%), shoulder (54\%), ankles/feet (49\%), hands/wrists (49\%), and hips/thigh/buttocks (46\%) were the most commonly reported areas of discomfort. Eighty-five percent of subjects reported pain in multiple joints. The most common joint combinations of reported pain were knee-low back (76\%), knee-shoulder (54\%), kneehands/wrist (49\%), and knee-ankles/feet (49\%). Also, 35\% of respondents reported the following joint pain combinations that did not involve the knee: low back-shoulder, low back-hips/thighs/buttocks, low backhands/wrists, low back-ankles/feet, and hips/thighs/buttocks-ankles/feet.

Subjects who reported back pain were also more likely to report pain in other joints (see Figure 3). Only subjects with back pain reported neck $(p=.06)$ and elbow $(p=.19)$ pain, and the large majority of subjects with shoulder $(p=.04)$, hands/wrists $(p=.41)$, hips/thighs/buttocks $(p=.49)$, and ankles/feet $(p=.41)$ pain reported back pain.

\section{Discussion}

This study has addressed considerable gaps in the state of knowledge regarding back pain and knee problems in individuals with knee OA who are candidates for TKA surgery. Knee OA and the associated pain can lead to bone demineralization, muscle atrophy, joint pain, inflexibility, and loss of functional ability (Creamer, 2004; Goerres et al., 2005). Thus, preventing or delaying the onset of knee OA will improve the quality of life of patients and reduce the costs to society. Therefore, the objective of this study was to verify the presence and temporal relationship between back pain and knee OA.

Seventy-four percent of subjects with knee OA reported back pain, which first occurred approximately 10 years before their becoming candidates for TKA. This level of back pain among patients with knee OA is similar to that previously reported (54.6\%) by Wolfe et al. (1996). In addition, all but one subject reported the onset of back pain prior to TKA candidacy, and less than $15 \%$ of subjects felt that their worst back pain occurred after the onset of knee problems. This finding is consistent with epidemiologic studies that indicate the onset of back pain in the fifth decade, which appears to precede and possibly contribute to knee pain emerging in the sixth decade (Felson et al., 2000). Moreover, the large majority of respondents described their back pain as being either severe or very severe and more than half had visited a physician or back pain specialist during the previous 12 months. The severity of back pain among the unilateral TKA candidates is further illustrated by the fact that $24 \%$ of subjects had undergone at least one previous spinal surgery. In addition, correlation analysis revealed that 
spinal surgery was highly correlated with the severity and duration of low back pain and a reduction in work and leisure activity. The high prevalence of serious back pain among patients with knee OA indicates that prevention or early aggressive treatment of back pain may reduce or limit the development of knee pain, knee OA, and possibly the need for TKA.

It is important to consider combinations of joint pain, as $85 \%$ of respondents reported that pain was occurring in multiple joints. With the exception of knee pain, which was constant for all subjects, the most common joint pain combinations all included the low back, and subjects with back pain were more likely to report pain in all other joints (see Figure 3). More importantly, perhaps, 35\% of subjects with low back pain also reported pain in the weight-bearing hip and ankle joints, suggesting a possible biomechanical relationship. Thus, these results indicate that, in certain situations, research directed at evaluating back pain or knee pain in isolation may not be appropriate. Comparable comorbidities have been reported by Keenan et al. (2006). In that study, only $12.5 \%$ of respondents who reported joint pain experienced problems in a single joint. In addition, only about one of 11 respondents reported only knee pain or only back pain.

Figure 3: Comparison of joint pain between subjects with and without back pain.aStatistically significant $(p<$ $.05)$. bMarginally significant $(p<.10)$.

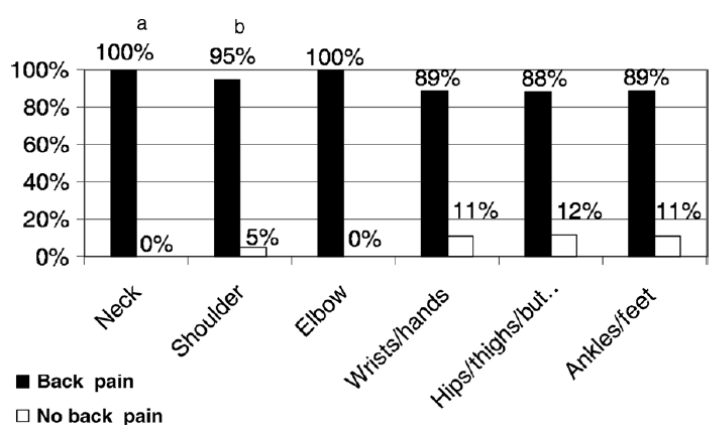

Although the main goal of this study was to determine the presence and temporal relationships between back pain and knee $\mathrm{OA}$, a number of interesting findings regarding back pain are worth discussion. In this study, $74 \%$ of the subjects reported a lifetime prevalence of back pain. This is consistent with several epidemiologic studies that report the lifetime prevalence of back pain between $70 \%$ and $80 \%$ (Centers for Disease Control and Prevention, 1994, 2001; R. A. Deyo, 1998). However, a majority (57\%) of the subjects in this study reported that they are currently experiencing low back pain. This value is a considerably larger percentage than can be found in the literature for persons in a comparable age range but is similar to the $31 \%$ of patients with knee OA experiencing back pain at the time of their knee OA examination (Wolfe et al., 1996). Specifically, Deyo et al. (2006) reported that $29.8 \%$ of persons aged $45-64$ years and $28.8 \%$ of persons aged $65-75$ years currently have back pain. Similarly, Nachemson (2004) reported that $30 \%$ of persons between the ages of 55 and 65 years were currently experiencing back pain.

Low back pain (74\%) was found to affect a larger percentage of respondents than upper back pain (21\%). Niemeläinen, Videman, and Battié (2006) reported similar results with $68 \%$ and $17 \%$ respondents reporting low back pain and upper back pain, respectively. This is worth mentioning because low back pain can have a considerable effect on the ability of persons to perform everyday tasks such as working and leisure activities. In fact, approximately $40 \%$ of subjects reported a reduction in work and leisure activities because of low back pain, and low back injuries, in general, are the most common musculoskeletal complaint in the aging workforce (Zuhosky et al., 2007). This is important to note, as about one third of respondents are still currently employed even though the average age of subjects is greater than 60 years. 


\section{Implications for Future Research}

Although back pain precedes OA treatment by an average of 10 years in $74 \%$ of questioned subjects, the relationships between the development and progression of unilateral knee OA and back pain are still unclear at this time. If one joint hurts, individuals will attempt to compensate in order to minimize their pain through changes in gait, motion, or other biomechanical adaptations (Janda, 1968; Watelain, Dujardin, Babier, Dubois, \& Allard, 2001). Patients who experience sciatic pain radiating to one limb have been observed to transfer force to the limb without pain, causing asymmetry in motion and muscle recruitment (Al-Eisa, Egan, Deluzio, \& Wassersug, 2006a, 2006b; Kulkarni, Gaine, Buckley, Rankine, \& Adams, 2005). Another study by Keenan et al. (2006) found that persons with both back and knee pain were 10 times more likely to have difficulty walking and standing than persons without back or knee problems. Future studies will include biomechanical analyses of common functional tasks such as walking and rising from a chair among patients with back pain and/or knee OA, and this line of research could potentially lay the ground work for developing interventions to minimize the impact of back pain and/or knee OA.

The results of this study may also have implications for the bedside orthopaedic nurse. This study indicates that back pain may be the harbinger of knee OA and may be an important predictor in the evolution of knee OA to the point of indicating surgical intervention for this disease. This study provides preliminary evidence that supports the theory of crossed syndrome in which neuromuscular imbalance in one area of the body predicts eventual dysfunction in another part of the body (Morris, Greenman, Bullock, Basmajian, \& Kobesova, 2006). The results of this study allow orthopaedic nurses to inform their patients with back pain that they may be at increased risk for knee OA and may wish to reduce risk factors for this condition. Orthopaedic nurses may wish to advise patients with back pain to attain and then maintain a healthy weight and engage in a program of regular physical activity emphasizing strengthening the core and large muscle groups in the lower extremities (Messier et al., 2004).

\section{Limitations}

The study included only subjects with unilateral knee OA and, as a result, the temporal relationship between low back pain and $O A$ in one knee was determined from retrospective, self-reported questionnaires. Another approach would be to complete a prospective study on patients with back pain to measure how many develop unilateral knee $\mathrm{OA}$, but this approach would involve considerable time and associated costs.

The purpose of this study was to determine the temporal relationship between low back pain and knee OA; thus, personal factors such as body mass index that could potentially be considered causal for both low back pain and knee OA were not of interest in this particular study.

Another main limitation is that all data concerning back pain were self-reported via the SNQ and not based on clinical diagnosis. However, because back pain is quite a subjective phenomenon and no single definition of back pain is consistently accepted in back pain research, self-report may be adequate (Kopec, Sayre, \& Esdaile, 2004). The SNQ also has been found previously to be valid when comparing self-report to clinical examination (Baron et al., 1996; Kuorinka et al., 1987) and the validity and internal reliability of the current results have also been affirmed through an acceptable Cronbach's alpha value of .836 .

Finally, the temporal relationship between back pain and unilateral knee OA is based on the time frame when the subject became a candidate for TKA, not when the onset of severe knee pain occurred. However, a recent study by Rudan, Harrison, and Grant (2009) reported that, on average, patients underwent unilateral TKA surgery within 8 months of deciding that their affected knee pain had reached an unbearable level. Because the vast majority of subjects in the current study reported that the onset of back pain occurred approximately a decade before TKA surgery, the temporal relationships described in this study are reasonably valid. 


\section{Conclusions}

The objective of this study was to investigate the presence and temporal relationship between back pain and unilateral knee OA. Seventy-four percent of subjects with knee OA reported back pain, which first occurred approximately 10 years before their becoming candidates for TKA. This information is a fundamental first step in determining whether such a causal relationship between back pain and unilateral knee OA exists. To determine whether a causal relationship is present, a temporal relationship must be identified (along with other factors). This study is the first step toward quantifying that temporal relationship and future studies will look to assess physical/biomechanical factors.

\section{Acknowledgment}

The study was supported by a grant from the NIH (NINR) R01 R008135-01A2. The content has not been previously published and all identifying information for study participants has been removed.

\section{References}

Al-Eisa E., Egan D., Deluzio K., Wassersug R. (2006a). Effects of pelvic asymmetry and low back pain on trunk kinematics during sitting: A comparison with standing. Spine, 31(5), E135-E143.

Al-Eisa E., Egan D., Deluzio K., Wassersug R. (2006b). Effects of pelvic skeletal asymmetry on trunk movement. Spine, 31(3), E71-E79.

Baron S., Hales T., Hurrell J. (1996). Evaluation of symptom surveys for occupational musculoskeletal disorders. American Journal of Industrial Medicine, 29(6), 609-617.

Bigos S., Bowyer O., Braen G., Brown K., Deyo R., Haldeman S. (1994). Acute low back problems in adults [Clinical Practice Guideline No. 14]. Rockville, MD: Agency for Health Care Policy and Research, Public Health Service, US Department of Health and Human Services, 95-0642.

Bureau of Labor Statistics. (2008). Table 5. Number of nonfatal occupational injuries and illnesses involving days away from work by selected injury or illness characteristic and major industry sector, 2008. Washington, DC: U.S. Department of Labor.

Centers for Disease Control and Prevention. (1994). Arthritis prevalence and activity limitations, United States, 1990. Morbidity and Mortality Weekly Report, 43(24), 433-438.

Centers for Disease Control and Prevention. (2001). Prevalence of disabilities and associated health conditions among adults, United States, 1999. Morbidity and Mortality Weekly Report, 50(7), 120-125.

Creamer P. (2004). Current perspectives on the clinical presentation of joint pain in human OA. Paper presented December 2, 2004, at the Novartis Foundation Symposium Basel, Switzerland.

Deyo R., Mirza S., Martin B. (2006). Back pain prevalence and visit rates: estimates from US National Surveys, 2002. Spine, 31(23), 2724-2727.

Deyo R. A. (1998). Low back pain. Scientific American, 8, 49-53.

Felson D. T., Lawrence R. C., Dieppe P. A., Hirsch R., Helmick C. G., Jordan J. M., Fries J. F. (2000). Osteoarthritis: new insights. Part 1: the disease and its risk factors. Annals of Internal Medicine, 133(8), 635-646.

Felson D. T., Zhang Y. (1998). An update on the epidemiology of knee and hip osteoarthritis with a view to prevention. Arthritis \& Rheumatism, 41(8), 1343-1355.

Goerres G., Häuselmann H., Seifert B., Michel B., Uebelhart D. (2005). Patients with knee osteoarthritis have lower total hip bone mineral density in the symptomatic leg than in the contralateral hip. Journal of Clinical Densitometry, 8(4), 484-487.

Ho C. W., Chen L. C., Hsu H. H., Chiang S. L., Li M. H., Jiang S. H., Tsai K. C. (2005). Isokinetic muscle strength of the trunk and bilateral knees in young subjects with lumbar disc herniation. Spine, 30(18), E528-E533.

Janda V. (1968). Postural and phasic muscles in the pathogenesis of low back pain. Paper presented Sept 14-19, 1969 , at the Proceedings of the XIth Congress ISRP, Dublin.

Keenan A. M., Tennant A., Fear J. O. N., Emery P., Conaghan P. G. (2006). Impact of multiple joint problems on daily living tasks in people in the community over age fifty-five. Arthritis \& Rheumatism, 55(5), 757-764. 
Kopec J., Sayre E., Esdaile J. (2004). Predictors of back pain in a general population cohort. Spine, 29(1), 70-78.

Kulkarni J., Gaine W., Buckley J., Rankine J., Adams J. (2005). Chronic low back pain in traumatic lower limb amputees. Clinical Rehabilitation, 19(1), 81-86.

Kuorinka I., Jonsson B., Kilbom A., Vinterberg H., Biering-Sorensen F., Andersson G., Jørgensen K. (1987). Standardised Nordic questionnaires for the analysis of musculoskeletal symptoms. Applied Ergonomics, 18(3), 233-237.

Lawrence R. C., Helmick C. G., Arnett F. C., Deyo R. A., Felson D. T., Giannini E. H., Wolfe F. (1998). Estimates of the prevalence of arthritis and selected musculoskeletal disorders in the United States. Arthritis \& Rheumatism, 41(5), 778-799.

Lee J. H., Ooi Y., Nakamura K. (1995). Measurement of muscle strength of the trunk and the lower extremities in subjects with history of low back pain. Spine, 20(18), 1994-1996.

Liikavainio T., Isolehto J., Helminen H. J., Perttunen J., Lepola V., Kiviranta I., Komi P. V. (2007). Loading and gait symmetry during level and stair walking in asymptomatic subjects with knee osteoarthritis: Importance of quadriceps femoris in reducing impact force during heel strike? The Knee, 14(3), 231-238.

Messier S., Loeser R., Miller G., Morgan T., Rejeski W., Sevick M., Williamson J. D. (2004). Exercise and dietary weight loss in overweight and obese older adults with knee osteoarthritis: The Arthritis, Diet, and Activity Promotion Trial. Arthritis and Rheumatism, 50(5), 1501-1510.

Morris C., Greenman P., Bullock M., Basmajian J., Kobesova A. (2006). Vladimir Janda, MD, DSc: tribute to a master of rehabilitation. Spine, 31(9), 1060-1064.

Nachemson A. (2004). Epidemiology and the economics of low back pain. Philadelphia, PA: Lippincott Williams \& Wilkins.

Niemeläinen R., Videman T., Battié M. (2006). Prevalence and characteristics of upper or mid-back pain in Finnish men. Spine, 31(16), 1846-1849.

Rudan J., Harrison M., Grant H. (2009). Determining patient concerns before joint arthroplasty. The Journal of Arthroplasty, 24(7):1115-1119.

Salerno D., Copley-Merriman C., Taylor T., Shinogle J., Schulz R. (2002). A review of functional status measures for workers with upper extremity disorders. British Medical Journal, 59(10), 664-670.

Snook S., Webster B. (1987). The cost of disability. Clinical Orthopaedics, 221, 77-84.

Suter E., Lindsay D. (2001). Back muscle fatigability is associated with knee extensor inhibition in subjects with low back pain. Spine, 26(16), E361-E366.

Topp R., Swank A., Quesada P., Nyland J., Malkani A. (2009). The effect of prehabilitation exercise on strength and functioning after total knee arthoplasty. Physical Medicine and Rehabilitation, 1, 729-735.

Watelain E., Dujardin F., Babier F., Dubois D., Allard P. (2001). Pelvic and lower limb compensatory actions of subjects in an early stage of hip osteoarthritis. Archives of Physical Medicine and Rehabilitation, 82(12), 1705-1711.

Wegener S. T., Belza B. L., Gall E. P. (Eds.). (1996). Clinical care in rheumatic diseases. Atlanta, GA: American College of Rheumatology.

Wolfe F., Hawley D., Peloso P., Wilson K., Anderson J. (1996). Back pain in osteoarthritis of the knee. Arthritis Care \& Research, 9(5), 376-383.

Zuhosky J. P., Irwin R. W., Sable A. W., Sullivan W. J., Panagos A., Foye P. M. (2007). Industrial medicine and acute musculoskeletal rehabilitation. 7. Acute industrial musculoskeletal injuries in the aging workforce. Archives of Physical Medicine and Rehabilitation, 88(3S1), 34-39. 